\title{
Rain Fade Estimations for the X-Band Satellite Communication Link in the Tropics
}

\author{
A. C. M. Nuroddin, A. F. Ismail, K. Abdullah, K. Badron, M. Ismail, and W. Hashim
}

\begin{abstract}
The X-band satellite communication (satcom) has been conventionally set aside for military and government organizations. It is also commonly known as the military band. The attributes of an X-band satcom hardware are expected to be designed specifically for military operations and they are expected to differ very much to those of commercial frequencies. The satcom will be likely to be exclusively designed to support smaller, low powered, tactical terminals deployed across various theatres of operation. In addition, $\mathrm{X}$-band link is also anticipated to offer a more substantial increased of system capacity due to its higher frequencies compared to the forerunner S-band and C-band. The X-band satcom technology is drawing growing interest from military users including of the Malaysian authorities. However, there are many aspects of $X$-band that are harder to realize than of those of at lower frequencies. $X$-band frequencies certainly have higher atmospheric propagation losses, higher RF losses, and certainly much severe signal degradation due to rain. It is would be in the best interest of the satellite designers and engineers alike to accurately appraise the challenges of an $\mathrm{X}$-band satcom link especially in the case of tropical regions where heavy rains are copious whilst the required technological advancements are in pursuit.
\end{abstract}

Index Terms - Rain attenuation, satcom, tropical region, X-band.

\section{INTRODUCTION}

The $\mathrm{X}$-band is a subdivision of the microwave radio region of the electromagnetic spectrum. In the instance such as in communication engineering, the frequency range of X-band is rather broadly set at approximately between 7.0 to 11 gigahertz $(\mathrm{GHz})$. X-band satcom are now commonly employed by leading nations as part of the integral set up of their mission critical communications where loss of communications is not an option [1]. In almost all cases, besides the requirement to strategically dimension the terminals' physical size, the $\mathrm{X}$-band satcom is also specifically designed to operate with high performance in remote and harsh locations that has no access to traditional telephony infrastructure; including naval and maritime platforms. The Malaysian government intends to

Manuscript received February 10, 2013; revised April 17, 2013.

A. C. M. Noruddin, A. F. Ismail, K. Abdullah, and K. Badron are with the International Islamic University Malaysia, P.O. Box 10, 50728 Kuala Lumpur, Malaysia (e-mail: amirah@iium.edu.my, af_ismail@iium.edu.my, khaizuran@iium.edu.my, khairayu@iium.edu.my)

M. Ismail is with the Malaysia Space Centre, National Space Agency (ANGKASA), Lot 2233, Jalan Turi, Sungai Lang, 42700 Banting, Selangor, Malaysia (e-mail: maszlan@angkasa.gov.my).

W. Hashim is with the Malaysian Institute of Microelectronic Systems (MIMOS Berhad), Kuala Lumpur, 57000 Malaysia (e-mail: wahidah.hashim@mimos.my). immediately acquire X-band satellite capabilities to enhance the Malaysian Armed Forces' communication network [2]. The facilities are considered vital, particularly in ensuring transmission and reception of secured confidential information from military warfare assets distributed strategically across various landscapes.

In designing the new satellite links, the performance predictions of the satellite are vital step to ensure the reliability of the systems. It is very critical to be capable to predict accurately and encountered the impairment of the given link in order to devise the services efficiently. The predicted value of signal loss and fading are commonly utilized in the process of establish the satellite design parameters [3]. Performance is usually expressed as the expected quality of the channel for a very high percentage of time (at least a month and usually a year). For satellite systems, that level achieved is commonly what is called "clear sky".

Instances of design parameter are the power requirements of the equipment, the antenna characteristics and the service range or the hop distance. These design parameters can be ascertained and from them the performance of a service is stipulated for a particular percentage of the time. The performance can be specified for instance, at availability of $99 \%$ of time at a given receiving locality or at a specified percentage of locations within a reception area. Availability is the ratio typically associated with the percentage of the total time a service is enabled or being used, or is available to be utilized during a given interval to the length of the interval.

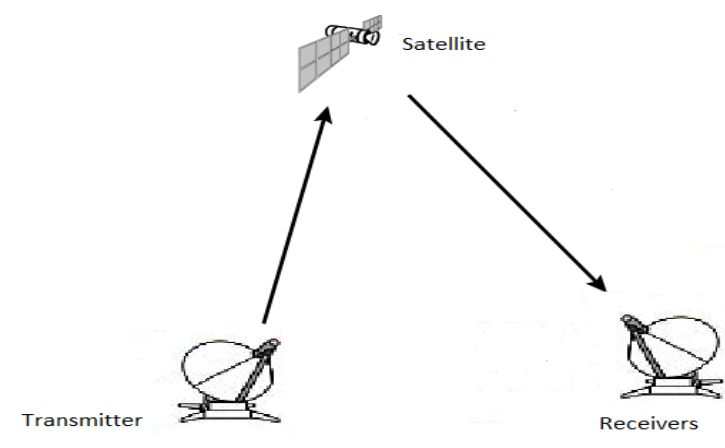

Fig. 1. Basic segment of a satellite communication link.

In satellite communication terminologies, the link availability is usually defined as a percentage of a year when the link will perform as per the required Bit Error Rate (BER). In the case of $99 \%$ availability for a year, it states that the link will be accessible for 867.24 hours and unavailable for 87.6 hours (8760 - 87.6 hours / 8760 hours x 100). Equally important, other designation such as the level of interfering signals exceeded for some small percentage of the time, for 
instance at $0.1 \%$, also need to be forecasted, again at the reception point or location of concern. Predictions are employed in order to know whether a satisfactory service will be provided at the involved reception point or area and also for spectrum allocation to avoid mutual interference with other systems occupying the same frequency band.

\section{TROPICAL RAIN FADE ESTIMATIONS}

Radiowave propagation prediction assumes a very significant part in the links design and eventually determines performance of space communication systems. The X-band allotment plan for Malaysia according the International Telecommunications Union (ITU) Appendix 30B includes assignment of frequency bands as high as $8.4 \mathrm{GHz}$. The operation of high frequency such as X-band encounters the existence of stronger electromagnetic interference concerning the radio signals and atmospheric hydrometeors especially for communication and broadcast purposes [4]. These instances will without doubt disfigure the performance of such high frequency satellite communication systems. Several models have been recommended for predicting rain induced attenuation statistics. Among presently available prediction procedures are the models recommended by the Radiocommunications sector of the International Telecommunication Union (ITU-R) [5], the Dissanayake, Allnutt and Haidara (DAH) rain induced attenuation model [6], the Crane-Global model [7] and the Crane-Two Component model [8].

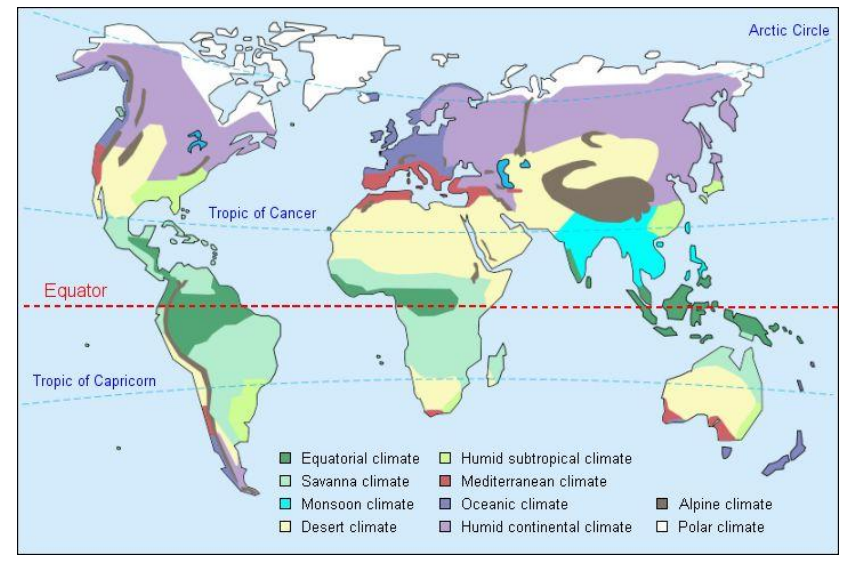

Fig. 2. World map of koppen climate classification [9].

Preliminary works on performance prediction of a future $\mathrm{X}$-band Earth-space link for Malaysia is included in this paper. The latest ITU-R model in force, published in October 2009 is highlighted and to be used to estimate performance of such systems operating in tropical climate environment. This procedure is the most up-to-date ITU-R method published to carry out attenuation prediction due to precipitation along a slant propagation path. The model is identified as Recommendation ITU-R P.618-10 - 'Propagation Data and Prediction Methods Required for the Design of Earth-Space Telecommunication Systems'. The technique currently implemented in ITU-R prediction model is based on the estimation of the attenuation exceeded at $0.01 \%$ of the time $A_{0.01}$, which is stipulated from the rainfall rate exceeded at the same time exceedance percentage, $R_{0.01}$. From a theoretical point of view, the notion of equiprobable analysis is not coherent with meteorological information and not entirely agreeable. Nonetheless, the exactness found in previous measurements campaigns and studies when using the prediction method is somewhat consistent with the quality and variability of available rain intensity data [10].

For a given amount of rainfall rate at 0.01 time exceedance percentage R0.01, the specific attenuation $\gamma \mathrm{R}$ is determined mathematically. When multiplied with the effective path length $L_{E}$, the corresponding attenuation value at $0.01 \%$ time exceedance $A_{0.01}$ is yielded. The schematic presentation of an Earth-space path delineating the parameters to be incorporated into the attenuation prediction procedures is shown in Fig. 3.

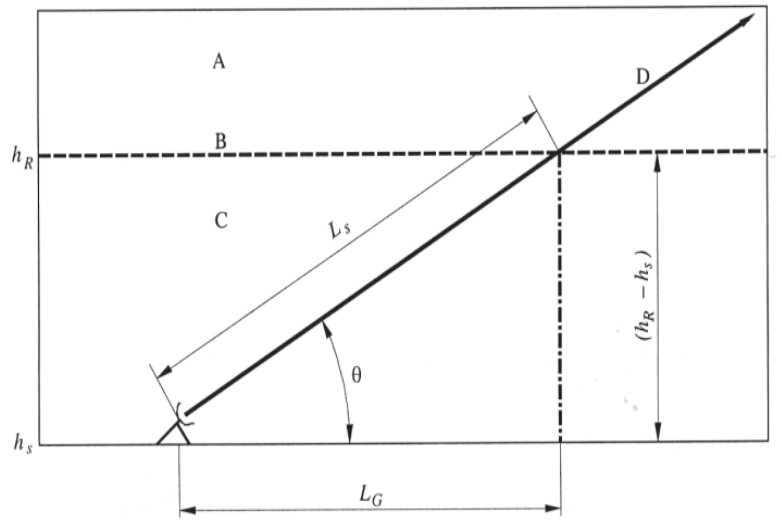

Fig. 3. Schematic presentation. A: frozen precipitation, B: rain height, C: liquid precipitation, D: Earth-space path, $L_{G}$ : horizontal projection, $L_{S}$ : slant-path length, $h_{r}$ : rain height, $h_{s}$ : station height, $\theta$ : elevation angle [2].

The set expression for the approximation of $A_{0.01}$ is founded on two assumptions. With reference to the Fig. 3, the first assumption is that the spatial structure of rain can be fashioned by equivalent rain cell; with a rectangular cross-section of equivalent length $L_{\mathrm{G}}$ and effective height $h_{\mathrm{R}}-h_{\mathrm{S}}$ in the plane of the path. The following hypothesis is that the equivalent rain cell can presume any position with respect to the path with equal probability.

\section{ESTIMATION PROCEDURES}

Diverse propagation parameters are required in planning of Earth-space systems operation in either the Earth-to-space or space-to-Earth direction, have to be predicted reliably. For a probable future satellite-Earth link to be operating in Johor Bahru, one of the cities in the southern part of Malaysia, the theoretical assessments of its performance had been deliberated methodically using the following procedures.

TABLE I: EARTH STATION AND SATELLITE INFORMATION

\begin{tabular}{|c|c|}
\hline Possible Terminal Description & Potential Satellite Location \\
\hline $\begin{array}{c}\text { longitude (degree), } \\
l_{e s}: 103.38^{\circ} \mathrm{E}\end{array}$ & $\begin{array}{c}\text { longitude (degree), } \\
l_{s t}: 91.5^{\circ} \mathrm{E}\end{array}$ \\
\hline latitude $($ degree$)$, & frequency $(\mathrm{GHz})$, \\
$\varphi: 1.33^{\circ} \mathrm{N}$ & $f .4$ \\
\hline $\begin{array}{c}\text { station height above mean sea } \\
\text { level of the }(\mathrm{km}), \\
h_{s}: 0.018\end{array}$ & polarization: vertical \\
\hline
\end{tabular}

The subsequent write-up highlights and involves 
adaptations of the ITU-R P.618-10 for the sake of readability and clarity. In the latest version of ITU-R prediction method, the vertical structure of rain is taken into account by the use of an effective rain height $h_{R}$, obtained from experimental data, in the expression of $L_{S}$. For vertical paths, the effective path length corresponds to the effective rain height, which at any latitude may diverge from the $0^{0} \mathrm{C}$ isotherm height $h_{F R}$, as indicated in ITU-R Recommendation, P.839-3 - 'Rain Height Model for Prediction Methods' [11]. Numerous methods have been proposed by previous researchers in order to take into account the vertical structure variability of rain. Few of these techniques can be regarded as an extension of those previously developed for terrestrial paths [12]. Whereas some had proposed rain height determination based on investigation on the rain structure itself [13]. Malaysian researchers had conducted preliminary investigation at various local locations using the Tropical Rainfall Measuring Mission (TRRM) satellite and meteorology radars in the hope to identify the actual effective rain height [14] and [15]. The rainfall rates $R_{0.01}$ at time exceedance of $0.01 \%$ from the new climatic zone map of ITU-R Recommendation P.837-6 that equals to $100 \mathrm{~mm} \mathrm{hr}^{-1}$ was utilized in estimating predicted attenuation values [16].

1) Computation of the elevation angle $\theta$, for the Earth-space link:

$$
\theta=\tan ^{-1}\left[\frac{\cos \left(l_{s t}-l_{e s}\right) \cos (\varphi)-0.45}{\sqrt{1-\cos ^{2}\left(l_{s t}-l_{e s}\right) \cos (\varphi)}}\right]
$$

Calculation of the polarization angle $\tau$ :

$$
\tau=\tan ^{-1}\left[\frac{\sin \left|l_{s t}-l_{e s}\right|}{\tan \varphi}\right]
$$

2) The effective rain height, $h R$, for the latitude of the station $\varphi$ was established according to ITU-R recommendation:

$$
h_{R}=h_{0}+0.36 k m
$$

The ITU-R Recommendation P.839-3 outlines that $h_{0}$ for Malaysia equals to $4.5 \mathrm{~km}$

1) For $\theta \geq 5^{\circ}$ calculation of the slant-path length $L s$, below the rain height is as follows:

$$
L_{s}=\frac{\left(h_{R}-h_{S}\right)}{\sin \theta}
$$

2) Computation of the horizontal projection, $L_{G}$ of the slant-path length from:

$$
L_{G}=L_{S} \cos \theta
$$

3) Calculation of the $k$ and $\alpha$ values using the frequency-dependent coefficients, $k_{H}, k_{V}, \alpha_{H}$, and $\alpha_{V}$ from Table I of the ITU-R P.838-3.

Based on postulation of spherical drops, values of $k$ and $\alpha$ have been determined at various frequencies between $1 \mathrm{GHz}$ to $1000 \mathrm{GHz}$ for several drop temperatures and drop size distributions. The calculations were carried out by presuming oblate spheroidal drops, aligned with a vertical symmetry axis and with dimensions related to equal volume spherical drops. Values of $k$ and $\alpha$ coefficients based on the Laws and Parson's rain drop size distribution and a drop temperature of $20^{\circ} \mathrm{C}$ have also been determined and incorporated in Table I of Recommendation ITU-R P.838-3[17]. The table also comprises other values for horizontal and vertical polarization of $k$ and $\alpha$ at various frequencies.

Values of $k$ and $\alpha$ at frequencies other than those in the table can be approximated by interpolation using logarithmic scale for frequency $f$, a logarithmic scale for $\mathrm{k}$, and a linear scale for $\alpha$. For linear and circular polarization, and for all path geometries, the $k$ and $\alpha$ coefficients for the specific attenuation equation can be determined from using the following equations:

$$
\begin{gathered}
k=\left[k_{H}+k_{V}+\left(k_{H} k_{V}\right) \cos ^{2} \theta \cos 2 \tau\right] / 2 \\
\alpha=\left[k_{H} \alpha_{H}+k_{V} \alpha_{V}+\left(k_{H} \alpha_{H} k_{V} \alpha_{V}\right) \cos ^{2} \theta \cos 2 \tau\right] / 2 k
\end{gathered}
$$

where $\theta$ is the path elevation angle and $\tau$ is the polarization tilt angle in relation to the horizontal as in (2) $\left(\tau=45^{\circ}\right.$ for circular polarization).

1) The specific attenuation, $\gamma_{R}$, using the frequency-dependent coefficients determined above and the rainfall rate, $R_{0.01}$ was acquired by using (1).

Investigators [18] have reported that the relationship between specific attenuation ' $A$ ' or ' $\gamma_{R}$ ' and rainfall rate $R$ can be estimated by using the power-law.

$$
\gamma_{R}=k\left(R_{0.01}\right)^{\alpha}
$$

2) Determination of the horizontal reduction factor, $r_{0.01}$, for $0.01 \%$ of the time:

$$
r_{0.01}=\frac{1}{1+0.78 \sqrt{\frac{L_{G} \gamma_{R}}{f}}-0.38\left(1-e^{-2 L_{G}}\right)}
$$

3) Computation of the vertical adjustment factor, $v_{0.01}$, for $0.01 \%$ of the time:

$$
\zeta=\tan ^{-1}\left(\frac{h_{R}-h_{s}}{L_{G} r_{0.01}}\right)
$$

Since the $\zeta>\theta$, therefore the reduced length $L_{R}$ was calculated according to;

$$
L_{R}=\frac{L_{G} r_{0.01}}{\cos \theta}
$$

In the case of Malaysia, its $\varphi<36^{\circ}$, hence

$$
\chi=36-|\varphi|
$$




$$
v_{0.01}=\frac{1}{1+\sqrt{\sin \theta}\left(31\left(1-e^{-(\theta /(1+\chi))}\right) \frac{\sqrt{L_{R} \gamma_{R}}}{f^{2}}-0.45\right)}
$$

1) Determination of the effective path length is:

$$
L_{E}=L_{R} v_{0.01}
$$

2) The anticipated attenuation exceeded for $0.01 \%$ of an average year is then determined using:

$$
A_{0.01}=\gamma_{R} \cdot L_{E}
$$

where the effective path length $\mathrm{L}_{\mathrm{E}}$ is the resultant of slant path length, horizontal path reduction factor $r_{0.01}$ and vertical path reduction factor $v_{0.01}$. The empirical expression of (15) is then employed for scaling of other time percentage, in order to provide a comprehensive prediction of rain induced attenuation distribution.

3) The predicted attenuation at other time percentages of an average year, in the range from $0.001 \%$ up to $1 \%$, is inferred from value in step 11 above; in keeping with the following conditions:

For $p<1 \%$ and $|\varphi|<36^{\circ}$ and $\theta \geq 25^{\circ}$ :

$$
\beta=-0.005(|\varphi|-36)
$$

and the estimated attenuation is:

$A_{p}=A_{0.01}\left(\frac{p}{0.01}\right)-\left(0.655+0.033 \ln (p)-0.045 \ln \left(A_{0.01}\right)-\beta(1-p) \sin \theta\right)$

\begin{tabular}{|c|c|}
\hline Parameters & Values \\
\hline$R_{0.01}\left(\mathrm{~mm} \mathrm{hr}^{-1}\right):$ ITU-R P.837-6 & 100 \\
\hline$\theta\left({ }^{\circ}\right)$ & 75.92 \\
\hline$\tau\left(\left(^{\circ}\right)\right.$ & 83.57 \\
\hline$h_{R}(\mathrm{~km}):$ ITU-R P.839-3 & 4.86 \\
\hline$L_{S}(\mathrm{~km})$ & 4.99 \\
\hline$L_{G}(\mathrm{~km})$ & 1.21 \\
\hline$k_{H}:$ ITU-R P.838-3 & 0.00754 \\
\hline$K_{V}:$ ITU-R P.838-3 & 0.0070 \\
\hline$\alpha_{H}:$ ITU-R P.838-3 & 1.316 \\
\hline$\alpha_{V}:$ ITU-R P.838-3 & 1.29 \\
\hline$\alpha$ & 1.303 \\
\hline$K$ & 0.0071 \\
\hline$\gamma_{\mathrm{R}}(\mathrm{dB} / \mathrm{km})$ & 2.86 \\
\hline$r_{0.01}\left(\mathrm{~mm} \mathrm{hr}^{-1}\right)$ & 100 \\
\hline$\xi\left({ }^{\circ}\right)$ & 77.74 \\
\hline$\chi\left({ }^{\circ}\right)$ & 34.67 \\
\hline$v_{0.01}\left(\mathrm{~mm} \mathrm{hr}^{-1}\right)$ & 0.5283 \\
\hline$L_{R}(\mathrm{~km})$ & 4.30 \\
\hline$A_{0.01}(\mathrm{~dB})$ & 6.50 \\
\hline$\beta$ & 0.17335 \\
\hline
\end{tabular}

Table II itemizes the parameters determine in accordance to the ITU-R's recommendations.

TABLE II: CALCULATED PARAMETERS USING ITU-R RECOMMENDATIONS

\section{FINDINGS AND OBSERVATIONS}

In planning communications links, cumulative distributions may be the most applicable presentation format for the long-term data. For example, link availability or exceedance at a point can be established from its annual cumulative distribution. Accordingly, suitable rain induced attenuation margins can be identified which to be incorporated into the system in the effort to attain the desired link performance. The predicted rain fade estimation using ITU-R recommendation as well as incorporation of local data [15] and [19] namely the rain height of $5.4 \mathrm{~km}$ as well as rainfall rate of $164 \mathrm{~mm} \mathrm{hr}^{-1}$ can be viewed in Fig. 4 .

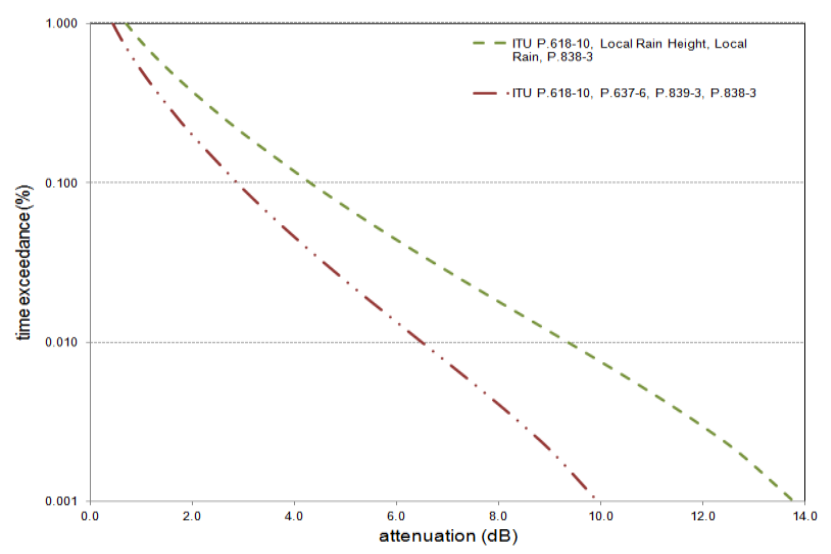

Fig. 4. Plot of ITU-R predicted attenuation statistics.

TABLE III: SELECTED TIME PERCENTAGES AND PREDICTED VALUES

\begin{tabular}{|c|c|c|}
\hline $\begin{array}{c}\text { Time exceedance } \\
(\%)\end{array}$ & $\begin{array}{c}\text { ITU-R Predicted } \\
\text { Attenuation }(\mathbf{d B})\end{array}$ & $\begin{array}{c}\text { ITU-R with local data } \\
\text { Predicted Attenuation } \\
(\mathbf{d B})\end{array}$ \\
\hline 1.000 & 0.45 & 0.70 \\
\hline 0.100 & 2.88 & 4.30 \\
\hline 0.010 & 6.50 & 9.35 \\
\hline 0.001 & 9.94 & 13.78 \\
\hline
\end{tabular}

Table III catalogues certain projected attenuation values for the likely future X-band satellite-Earth link in Malaysia. Preliminary results of possible rain induce-attenuation signal degradation to be experienced by an X-band link at Johor Bahru were produced. These initial outcomes suggested that due to the severity of the rain induced attenuation that will be confronted, the X-band satellite operation in Malaysia and others in tropical region may not be easily achievable to operate at $99.99 \%$ availability (equivalent to $0.01 \%$ time exceedance) to concur with the strict communication QoS requirement. Considerable substantial margin by today's technological advancement of somewhat more than $9 \mathrm{~dB}$; has to be incorporated into the wireless communication link in order to cope with rain fading in such severe climate.

If X-band satellite communications is to be actually implemented, current and forthcoming studies should be immediately dedicated on identifying integrated solutions in the satellite's design i.e. transmission power level management, determination of appropriate reflector size, antennas configuration, radiating antenna technologies, steerable beam capability, etc. RF engineers can participate in the effort by exploring the use of one or more fading mitigation techniques to lessen the effect of rain induced attenuation. 


\section{CONCLUSION}

The use of X-band satcom will be materialized in Malaysia for the next few years. The X-band satcom facilities will be special digital communication means for the government or armed authorities to transmit a high data, sounds and videos between the receiving and transmitting antennas. In anticipation of the evolution towards the X-band for high data rate multimedia applications, among the main constraints of concern will be the rain fade. Initial studies on propagation impairment have identified that consequence is indeed be quite severe Malaysian climate i.e. tropical climates, so standard performances are expected be taxing to achieve in these regions. Production of predicted impairment statistics as been highlighted in this paper is therefore may be central and need to be taken into serious consideration in the future design and deployment of anticipated high frequencies satcom systems in the tropics.

\section{ACKNOWLEDGMENT}

The authors acknowledge the Research Management Centre of the International Islamic University Malaysia (IIUM) for the financial support and would like to express special appreciation to the National Space Agency of Malaysia for the technical guidance and assistance. The work is currently being supported in part by the International Islamic University Malaysia under Endowment Grant Type B2011.

\section{REFERENCES}

[1] J. N. Pelton, The Basics of Satellite Communications, International Engineering Consortium, $2^{\text {th }}$ edition, 2006.

[2] MAF Moves A Step Further With Own Satellite. [Online]. Available: http://www.bernama.com/bernama/v6/newsindex.php?id=925049

[3] B. R. Elbert, "Introduction to satellite communication," Artech House, 2008.

[4] J. E. Allnutt and P. Peregrinus "Satellite-to-ground radiowave propagation: Theory, practice, and system impact at frequencies above $1 \mathrm{GHz}, " 1989$.

[5] Recommendation ITU-R P.618-10, Propagation Data and Prediction Methods Required for the Design of Earth-space Telecommunication Systems, 2009

[6] A. Dissanayake, J. Allnutt, and F. Haidara, "A prediction model that combines rain attenuation and other propagation impairments along earth-satellite paths," IEEE Transactions on Antennas and Propagation, AP-45, pp. 1546-1558, 1997.

[7] R. K. Crane, "Modelling attenuation by rain in tropical region," International Journal of Satellite Communication, vol. 8, pp. 197-210, 1990.

[8] R. K. Crane and H. C. Shieh, "A two-component rain model for the prediction of site diversity improvement performance," Radio Science, vol. 24, pp. 641-655, 1989.

[9] Encyclopedia Britannica. [Online]. Available: http://global.britannica.com/EBchecked/topic/322068/Koppen-climate -classification

[10] J. S. Seybold, Introduction to RF Propagation, John Wiley and Sons, 2005.

[11] Recommendation ITU-R P.839-3, Rain Height Model for Prediction Methods, 2001

[12] W. Y. Li, V. Chandrasekar, and M. Thurai, "Sensitivity of dual-frequency rain DSD retrieval to particles in melting layer for space-borne radars," in Proc. IEEE International Conference on Geoscience and Remote Sensing Symposium, pp. 507-510, 2006.

[13] M. J. Leitao and P. A. Watson, "Method for prediction of attenuation on earth-space links based on radar measurements of physical structure of rainfall," IEE Proceedings F, vol. 133, pp. 429-440, 1986.
[14] M. A. N. Azlan, J. Din, and H. Y. Lam, "Rain height information from TRMM precipitation radar for satellite communication in Malaysia," in Proc. International Conference on Space Science and Communication, pp. 73-76, 2011 .

[15] N. H. H. Khamis, O. A. R. Sharif, Z. Hanzaz, and A. Baharom, "Determination of the melting layer from meteorological radar data in Malaysia," International Symposium on Microwave, Antenna, Propagation and EMC Technologies for Wireless Communications, pp. 1467-1470, 2007.

[16] Recommendation ITU-R P.837-6, Characteristics of Precipitation for Propagation Modelling, 2012.

[17] Recommendation ITU-R P.838-3, Specific Attenuation Model for Rain for Use in Prediction Methods, 2005.

[18] R. L. Olsen, D. V. Rogers, and D. B. Hodge, "The $\mathrm{aR}^{\mathrm{b}}$ Relation in the calculation of rain attenuation," IEEE Transactions on Antennas and Propagation, AP-26, pp. 318-329, 1978.

[19] A. Ismail and P. Watson, "Characteristics of fading and fade countermeasures on satellite-earth link operating in an equatorial climate with reference to broadcast applications," Microwave Antenna Propagation, IEEE, vol. 147, no 5, pp. 369-373, 2000.

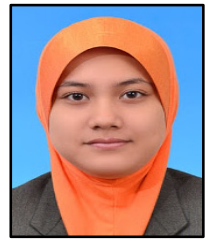

A. C. M. Nuroddin graduated top of the 2012 B.Eng in Communication Engineering class at the International Islamic University Malaysia, She is currently a research assistant whilst pursuing her MSc candidacy at the Electrical and Computer Engineering department, IIUM. Her research interests are wireless communication particularly on the assessment of signal degradation due to precipitation of the next generation wireless communication devices.

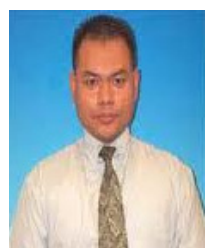

A. F. Ismail is a lecturer at the Department of Electrical and Computer Engineering, Faculty of Engineering, IIUM. He completed his bachelor degree studies in Electrical Engineering at Gannon University, Pennsylvania, USA with Cum Laude Latin honors. He holds MSc from University of Essex, UK and $\mathrm{PhD}$ from University of Bath, UK. His research interests include millimeter and microwave propagation studies and Cognitive Radio applications. He is a registered Professional Engineer with Board of Engineering Malaysia and also a Senior Member of the IEEE.

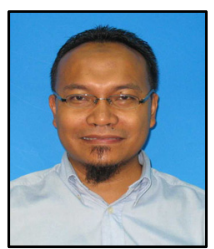

K. Abdullah obtained his BSc in Electrical Eng. from University of Ohio USA in 1997 and completed his ME in Electrical Eng. at Universiti Teknologi Malaysia in 2003. He received $\mathrm{PhD}$ in Electrical and Computer Eng from RMIT University, Melbourne, Australia. He is an assistant professor at faculty of Engineering, International Islamic University Malaysia. His research interests are in the area of Cognitive Radio as well as advance modulation design. He is a Senior Member of IEEE and member of IEM.

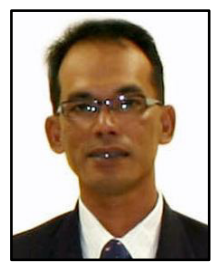

M. Ismail is the Malaysian National Space Agency director. He directs the satellite ground operation as well as the spacecraft testing facilities. He was the principal engineer for Malaysian Remote Sensing Satellites RazakSAT and TiungSAT. Maszlan received his BEng and MSc from the National University of Malaysia specializing in wireless and satellite communication. He is one of the committee members of IEEE Malaysian chapter and Asia-Pacific Regional Space Agency Forum.

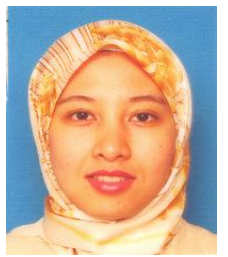

W. Hashim received his bachelor degree in Information Technology, Business Management and Language from University of York, UK in 1999. She then pursued her MSc in Multimedia Technology at University of Bath, UK in 2001. She completed her PhD studies from King's College London, UK in 2008 in the field of Telecommunication Engineering. She is currently a staff researcher at the Wireless Communication Cluster, MIMOS Berhad with focus in cognitive radio, WLAN, OFDM, space-time coding, MIMO systems and wireless system. 